\title{
A case study approach to understanding a remote undergraduate research program
}

\author{
Dina Zohrabi Alaee and Benjamin M. Zwickl
}

School of Physics and Astronomy, Rochester Institute of Technology, 84 Lomb Memorial Dr, Rochester, NY, 14623-5604

Due to the growing concerns surrounding the COVID-19 pandemic, colleges and universities either canceled or remotely hosted their 2020 National Science Foundation Research Experience for Undergraduates (REU) programs. This analysis is part of a larger study examining the impact of these fully remote experiences on professional and psychosocial factors such as mentees' sense of belonging, identity, and self-efficacy and their retention in STEM degree programs. We present a single-student case study and describe the dramaturgical analysis which centers on identifying five fundamental constructs within the data: objectives, conflicts, tactics, attitudes, and emotions. These items investigate what the participant in the remote REU program experienced and how this experience changed the ways in which he thinks about his future career decision making. Our analysis explored four different sub-narratives: lack of community in virtual REU, mentor support, perception of the "real" nature of the experience in a virtual format, and future career decision-making. The mentee reported that this experience was highly beneficial and that he developed a sense of belonging and identity, despite working remotely - often from his own bedroom.

2021 PERC Proceedings edited by Bennett, Frank, and Vieyra; Peer-reviewed, doi.org/10.1119/perc.2021.pr.Zohrabi_Alaee Published by the American Association of Physics Teachers under a Creative Commons Attribution 4.0 license. Further distribution must maintain the cover page and attribution to the article's authors. 


\section{INTRODUCTION}

In order to increase undergraduate students' persistence in STEM the National Science Foundation (NSF) established the first Research Experiences for Undergraduates (REU) program in 1980 [1-4]. These REU programs have provided an opportunity for undergraduate students to clarify their future career goals [5-7], facilitate their research-based skill development [8], learn a wide variety of content knowledge [8] as well as enhance psychosocial gains (e.g., identity and sense of belonging) [5-9]. Research suggests that there is a strong relationship between having a good in-person undergraduate research experience and positive future outcomes $[10,11]$. Although a variety of studies have explored the positive benefits of in-person REU programs, very little research has focused on remote REU experiences, in part because prior to COVID-19, they were rarely offered. However, due to the COVID-19 pandemic, there were no in-person REU programs in the summer of 2020; some institutions remotely hosted their REU programs while others canceled their programs. This analysis is a part of a larger study that describes a holistic view of the mentees' remote REU experience over a 10-week duration and its impact on psychosocial factors, learning outcomes, and career options. The purpose of this paper is to present a single-student case study that explores the remote REU experience, including the community, mentoring, whether it was perceived as a "real" or authentic experience, and how it led to changes in a student's career goals. While all of these factors play a role in any REU experience, the case study highlights the ways in which the virtual format specifically affected the experience.

\section{METHODOLOGY}

We asked 64 physics REU program coordinators about their REU format in summer 2020 and found that $N=8$ hosted a remote REU, $N=18$ were canceled, and $N=38$ provided no response and the status of their REU program was unclear from their website. Within each REU we recruited paired students and mentors. Data was gathered through weekly semistructured interviews with mentees ( 4 female, 6 male) and 8 paired male mentors from six programs. We recognized that this level of involvement was significant in the midst of all the other burdens of the COVID-19 pandemic, so all participants received a $\$ 20$ gift card after each completed interview. The interviewer tried to create a trusting and relaxed atmosphere between the interviewer and the participants to encourage participants to share their experiences. In this paper, we focus on 10 interviews with a single male student, Joe, and his paired mentor, Dr. Tom (both pseudonyms).

To explore Joe's experiences in-depth, he was interviewed at six successive points over the duration of the REU program and once after it finished. Additionally, his mentor was interviewed two times over the course of the REU program and once after it finished. Figure 1 shows the topic and duration for each week of the interview. To understand his responses during the REU experience, a dramaturgical coding approach was used [12]. Dramaturgical analysis focuses on identifying five fundamental constructs within the data: objectives, conflicts, tactics, attitudes, and emotions. Objectives refers to motives and goals. For instance, Joe said his goal for this REU experience was "to figure out if I wanted to spend time in a research setting." Conflicts refers to obstacles that prevent participants from achieving their objectives. For instance, Joe was unsure about his future career, saying, "I don't know what my dream job is." Tactics or strategies refers to dealing with conflicts to achieve the objectives. For instance, Joe was "planning taking the GRE" and had "talked to several professionals" in order to make his final decision about his future career path. Attitudes refers to participant's beliefs toward the conflicts. For instance he tried to "stay positive" about finding possible career options. Emotions refers to the feelings that a participant experiences. Joe expressed that the REU was "overwhelming" and he sometimes felt "stressed."

We began the data analysis process by reading each transcript to become familiar with the data. Once we immersed ourselves in the data, we broke down interview narratives week-by-week by assigning dramaturgical codes (objectives, conflicts, tactics, attitudes, and emotions). For instance, a tactic related to the "conflict" around career decision-making was studying for the GRE test during the summer. Across interviews we found that most of the dramaturgical codes centered around four "conflicts" that were resolved over the REU experience, and which became the four sub-narratives discussed in the findings.

\section{STORY OF JOE AND DR. TOM}

Joe is an incoming fourth-year student from a private liberal arts college. He is a 22-year-old male student of Chinese descent. During his freshman year, he was unsure about his major and took nine classes in eight different departments to find out what he liked. He did not take a college physics course until his sophomore year, which he found "extraordinarily difficult." Even though he "did not do well in the course", he was "interested in it" and he "decided to keep trying at it." He found out about the REU program from one of the professors at his home institution. He offered Joe a teaching assistant position in a lab course that Dr. Tom would teach in Fall 2020 while on sabbatical at Joe's home institution.

Dr. Tom is a male professor of physics at a R1 university, a director of an institute, and an experimentalist with decades of experience mentoring undergraduates. Joe briefly met Dr. Tom several months before the REU program started when Dr. Tom visited Joe's home institution as a colloquium speaker. During the REU program, Dr. Tom was Joe's primary mentor. Two other faculty members served as Joe's co-mentors and helped him with understanding the experiments and setup of the system. The mentors reported trying to provide a welcoming environment, such as "when Joe asked questions, we reply back to him quickly." Dr. Tom put a lot of emphasis on increasing Joe's motivation. It was important for him that Joe develop a deep interest in certain areas of research, the ability to ask the right questions, and a possible 


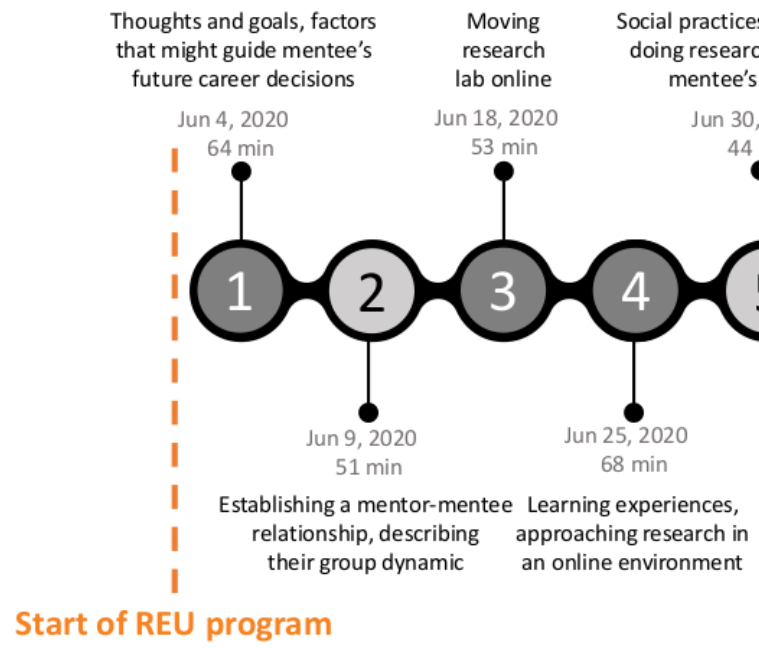

Mentee (7 interviews total)
Outcomes of the remote experience, understanding impact of REU on

mentee's future career paths experiences Jul 16, 2020 80 min

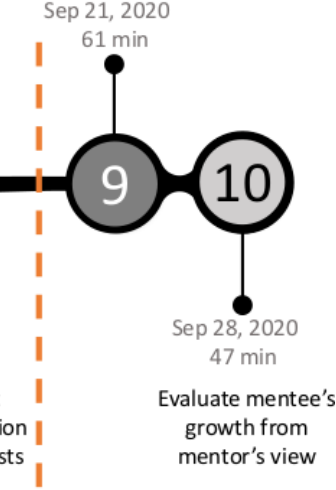

FIG. 1. Overview of Interview Study Design and Protocol Content.

conference presentation or publication.

\section{FINDINGS}

Through the dramaturgical coding process, four subnarratives emerged under the "conflicts" code: lack of community, mentor support, real REU experience in a virtual format, and future career decision making. In the following section, we present several example supporting these subnarratives identified across Joe's data.

a. Lack of community in virtual REU: One narrative that emerged from the data was the lack of community and social interactions, including communication between REU students. In the $1^{\text {st }}$ interview, Joe said he had heard that other in-person REU experiences supported community building, meeting new people, and making contacts. He wanted to be a part of a community like that, but "it seems a little more difficult to get that right now." Joe stated one of his main struggles was a lack of community and communication with other REU participants. "I've met the other REU participants on Zoom, but it doesn't seem like there's going to be much of a conversation happening... Like currently, we have a Slack, but no one's commenting on it." Another issue he faced was seeking and receiving timely feedback from his mentors. He said, "It's a little more difficult to email a question and get an immediate response, instead of having a conversation to understand something."

During the $3^{\text {rd }}$ interview, Joe felt "there is no community." According to Joe, during social events the REU participants didn't interact with each other because they were listening to lectures, and he wished they had some sort of "all groups' meeting" where they were able to present their work. In addition, he added "I'm working alone", and "I've not met any of the grad students working in this lab." In the $8^{\text {th }}$ interview, Joe explained that, due to a lack of social interaction, he did not perceive recognition from others as a "physics person". "Even when I'm doing research, I'm not showing it to anyone." However, Dr. Tom stated that "Joe is beginning to certainly think like a scientist." In the $9^{\text {th }}$ interview, which took place several weeks after the REU program finished, he stated that the sense of belonging to the physics community improved by being on campus again. He became "more comfortable in the [physics] community and because of that I became less stressed about interacting with the community...I feel I'm somewhat part of the bigger physics group because I understand how it works now. I am collaborating with some people. I know a finite number of researchers and exactly what they're doing. I've worked with them or I know the kind of research they're doing, so that's why I feel like that." Joe developed a sense of belonging through making scientific contributions and through communication with other group members. He still thought there weren't enough updates and check-ins with the REU coordinators and there was little connection between the REU students. He said, "There were 10 other REU students and I only knew what three of them did... I wish I had known more about other projects."

b. Mentor support impacted by virtual REU: Despite the virtual format of the REU program, we found evidence that the relationship Joe had with his mentor developed over the summer. It took effort for Joe to build that relationship with his mentor. However, by the end of the REU program, Joe counted on Dr. Tom for support, guidance, and feedback. During the $1^{\text {st }}$ interview, Joe felt motivated because his mentor valued "training the student rather than trying to get something published." He felt that the mentor-mentee relationship was going to be focused on helping him learn. In addition, Joe said one of his major goals for attending the remote REU program was getting "a good letter recommendation." In the $3^{\text {rd }}$ interview, his concern was repeating things that former 
graduate students and REU students did. He said, "I felt like I lost ownership of my project." However, after he had a conversation with Dr. Tom, he noticed Dr. Tom wanted him "to go in a very new direction." He said, "if I'm able to pull this off in the nine weeks... I'll be very proud of that. I would definitely feel like I have ownership over it." Dr. Tom stated that as a part of his mentoring philosophy he was trying to ask his students "to put things together and describe how it's working. They feel that they have done it, and they can tell us in detail about how things are operating and functioning and we're not the ones who always know what is going to happen." Although Joe said, "I do feel I've been getting a lot of guidance" he still added that "There's not that much discussion between him and I, unless I initiate it." Joe expressed concern about the amount that Dr. Tom lectured him. Despite ultimately finding the information useful, Joe worried about the use of their limited time together.

During the $4^{\text {th }}$ interview, Joe described his concerns about getting stuck, "I've been procrastinating a decent amount... And that coupled with I'm being unwilling to ask questions and say my ideas to Dr. Tom... I could just email him, and he'll respond pretty quickly." Dr. Tom added "We really function together to plan and improvise... We had to constantly be aware that we need to improvise, change, and adjust the direction of the research and the problems that we're trying to solve." But, Joe was still more comfortable asking a question in-person and over Skype or Zoom than emailing a question. He continued, "I think my hesitation to ask questions has been allowing me to get stuck for longer than I probably should." He dealt with this situation by being more independent (e.g., reading more papers) and trying to ask questions more often. Joe said after reaching out to his mentor he felt Dr. Tom "had a good ideas and I became unstuck."

As the REU program progressed, Joe felt his mentors gave him a lot more confidence after each meeting. They were "very positive" and "focused on explaining what that next step is going to look like." In addition, he described a situation in which he did something wrong, owned up to his mistake, and discussed it with Dr. Tom. Joe said, "his mentoring definitely changed my research behavior for the better." Although Joe met his mentors twice a week, Dr. Tom told him that they could meet more frequently and Joe thought "I think the opportunity is there. But I haven't felt comfortable asking for it." Joe's mentors shipped an entire experiment to his home so he could have some hands-on experimental work with electronics, despite the remote setting. Starting in the $6^{\text {th }}$ week, Joe's mentors shifted their focus to achieving the project's goals instead of asking Joe to define a personal set of goals. Joe thought that this shift was due to his performance and not progressing as far as planned. He also said his advisors had been trying to direct him to make an actual functional circuit. He said, "They see that I'm moving forward in the experimental part. So, I'm being pushed to do that more. I think both my advisors and I have been kind of going in the same direction."

In the $8^{\text {th }}$ interview, Joe decided to reach out to his men- tors more and emailed them his questions and shared visual images during their meetings. He said, "The speed of communication via email has been very fast on my mentors." During the final interview, Joe and Dr. Tom both explained the growth that happened in Joe's learning and his research skills. Joe also expressed being able to ask questions online and able to ask his mentors for help when he stuck on his project. He was happy with the results that he got from this experience. He continued that, "I felt that the majority of my satisfaction came from accomplishing things and knowing that, if I were to get stuck, I did feel confident that my mentors would be able to help me in the right direction."

c. Real REU experience in a virtual format: Joe had a real research experience over the course of the summer experience. The major focus of this narrative is whether or not the remote REU, despite many awkward limitations, still felt like a "real" research experience and if Joe's outcomes matched his expectations. In the $1^{\text {st }}$ interview, Joe said his goals for attending the REU program was to have a good research experience that taught him nonlinear dynamics and "get a good recommendation letter." In the $3^{\text {rd }}$ interview Joe talked about how easy it was to get distracted since he stayed at home. In order to deal with that, "half the room is the bedroom and the other half is an office." In the $6^{\text {th }}$ interview, Joe said due to the pandemic he had a chance to work from home and had quality time with his family which he found very beneficial. For instance, he said, "I have a sister who's now seven years old and I'm spending time with her for the first time in my life." Despite these positives, Joe still said, "I don't feel like I'm doing research. I am at home, I'm spending a lot more time with my family than I am with the research people." Because of that, he felt he was "just doing work in my house" but not doing real research.

In the $8^{\text {th }}$ interview, Joe still talked about the lack of physical connection to a laboratory environment, despite the fact that he had a chance to do some hands-on experimental work at home. Although it was difficult for him to determine when he was doing research, he felt he was making progress. He felt good since he was "getting stuff done" and "able to produce results." He talked about many aspects of his research as a constructive sign of doing actual research (e.g., explaining his research to his dad or the interviewer). After seven weeks Joe learned a lot and he could see himself using that knowledge in some capacity in the future. In the $9^{\text {th }}$ interview, Joe stated, "I was doing real research, because I think the ability to create something that's your own, whether that be an experiment, writing a code from the scratch, and observing the results of that code that you've written. I think because I was able to do that. I got real research experience." Additionally, Dr. Tom said, "Joe had a real research experience. I know that because he and I are working every day together now on this lab course. So, I know exactly a lot more about what he learned and what he did and I see that he is applying for graduate schools right now."

d. Future career decision-making impact of virtual $\boldsymbol{R E} \boldsymbol{U}$ : Our findings revealed similar benefits to in-person 
research experiences. The remote REU programs helped students to make career decisions. Joe's plans for his future career shifted over the course of the summer experience. During the $1^{\text {st }}$ interview, Joe worried about the difficulty of finding job in academia, so he wanted to "take a little bit of time to work in industry before going to graduate school" to see if he want to do that. Joe tried to figure out alternative options to graduate school, contacting people in the energy sector, looking at an engineering program at his college and research labs. He "used to feel anxious about it", but felt a lot less anxious since "knowing that there's other stuff out there and I don't have to continue education." When he was thinking about graduate school, he expressed worry about the GRE Physics subject test, "This summer I plan on studying for GRE... to see where my score is to see how far away I was from getting a reasonable score." Joe also talked about tension between him and his parents regarding the possibility of taking a gap year before starting graduate school. He decided to talk to them and made it clear that he had not yet made up his mind. In the $3^{\text {rd }}$ interview, Joe still expressed hesitation about his future career path. He started studying for the GRE Physics subject test. By the $8^{\text {th }}$ interview, Joe described looking for opportunities such as fellowships and research labs. He was thinking of either research experiences in labs or industry experiences with something connected to condensed matter physics for his future career. He said, "I think that I will go to graduate school at some point at least, either immediately after or a couple of years after graduating from college." He was motivated to pursue condensed matter research because he was generally interested in it, there is potential to "get a job that offers a lot of security", and there is an availability of condensed matter physics research in most graduate programs. If he attends graduate school, the location will be a major factor since his family wants him to attend a school closer to home.

By the $9^{\text {th }}$ interview, Joe said his perspective had clarified since being back on campus again and he wanted to go to graduate school right after graduating from college. He felt that being in graduate school would allow him to continue stay close to his family. Additionally, "I don't have to worry about the GRE anymore" because the GRE subject test was cancelled due to COVID-19. Joe said, "I definitely think that Dr. Tom has a strong influence on making my decision about graduate school." He told a lot of stories about his past graduate students and what they're doing now. Joe said, "There's just so many different ways that they're either the professors or they're working in research labs or in different things... It's just stuff that I really would like to be doing in the future as a career... I think another [influence] is just he's giving me a sense of how he does research... he's not always super stressed about everything. He's not overworking himself. This idea that you can be a researcher and not overwork yourself all the time is also quite enticing." By the the last interview, Joe described a detailed plan for developing his application materials, identifying potential programs, and soliciting recommendation letters.

\section{CONCLUSION}

The dramaturgical analysis was used to organize, understand, and tell the story of the experiences of one student who participated in a remote REU program in Summer 2020. In the early weeks of the program, Joe expressed concern about developing relationships with other REU students and his mentors in the remote format. Although the lack of student community persisted throughout the program, the research community grew gradually over the duration of the REU program. There was growth in the quality and frequency of the mentor-mentee interaction, but the lack of in-person contact made the relationship slower to develop. Regardless of his perceived lack of student community, the remote format allowed Joe to improve his research community and his relationship with his family while engaging in his learning. The case of Joe's findings indicates that overall, he regarded this experience as a "real" research opportunity and enjoyed it despite never setting a foot in Dr. Tom's laboratory.

Joe was unsure about his future career path during most weeks of the REU program. We found Joe developed a greater self-efficacy after this experience, which is likely to improve his academic performance and enhance persistence in the field of physics. These outcomes are consistent with evidence from multiple studies of in-person research experiences that found higher gains in several areas (e.g., selfefficacy or ability to work independently) [13]. After the REU program finished, he gained clearer ideas about his future career path. He started preparing application materials for graduate school, read articles related to his research, and enrolled in elective courses as a result of this research experience. These outcomes are similar to in-person research programs studies that showed higher gains in students' decisions around applying to graduate school after undergraduate research experience $[5,11,14]$.

This study has a number of limitations. The COVID-19 pandemic has changed every aspect of our lives and adds more pressure and challenges, which may limit the generalizability of some of our findings to virtual REU experiences that occur without the pressures of a pandemic. In addition, since our study was limited in size and scope, we were not able to explore a student population with diverse demographics. Our goal was to share the first snapshot of what was the reality of undergraduate research looks like in the remote situation and to encourage REU coordinators and mentors to consider the positive benefits of a remote format. Although the number of students participating in undergraduate research has increased $[10,15]$ there still may be significant barriers to access for some students with geographic constraints, family obligations, or health concerns that limit travel. Remote research experiences may provide way to expand access to research for more students.

\section{ACKNOWLEDGMENTS}

This work was supported by the National Science Foundation under Grant No. 1846321. 
[1] NSF, NSF's Research Experiences for Undergraduates (REU) Program: An Assessment of the First Three Years. National Science Foundation Report. (Forms and Publications Unit, Room 232, National Science Foundation, 1800 G St, 1990).

[2] NSF, Washington, D.C. , 13 (2013).

[3] C. R. Corley, The History Teacher 46, 397 (2013).

[4] H. Liand M. Abdelrahman (2015) pp. 26.992.1-26.992.8, iSSN: 2153-5965.

[5] D. Lopatto, Cell Biology Educationâ Life Sciences Education 3, 270 (2004).

[6] E. Seymour, A.-B. Hunter, S. L. Laursen, and T. DeAntoni, Science Education 88, 10.1002/sce.10131 (2004).

[7] A. B. Hunter, S. L. Laursen, and E. Seymour, Science Education 91, 36 (2007).

[8] C. M. Kardash, Journal of Educational Psychology 92, 191 (2000), place: US Publisher: American Psychological Association.

[9] S. Laursen, A. Hunter, H. Seymour, H. Thiry, and G. Melton,
Undergraduate Research in the Sciences: Engaging Students in Real Science. (Jossey-Bass, 2010).

[10] S. H. Russell, Evaluation of NSF Support for Undergraduate Research Opportunities: Follow-up Survey of Undergraduate NSF Program Participants : Draft Final Report. (SRI International, 2006).

[11] C. M. Kardash, M. Wallace, and L. Blockus, in Creating effective undergraduate research programs in science (Teachers College Press, New York, NY, US, 2008) pp. 191-205.

[12] J. Saldana, The Coding Manual for Qualitative Researchers. (Sage, Los Angeles, CA, 2009).

[13] D. Lopatto, CBE Life Sciences Education 6, 297 (2007).

[14] J. Jonides, W. von Hippel, J. Lerner, and B. Nagda, Paper presented at the American Psychological Association Annual Meeting, Washington, DC. , 27 (1992).

[15] E. Boyer, The Boyer Commission on Educating Undergraduates in the Research University, Reinventing Undergraduate Education: Three Years after the Boyer Report (Stony Brook, NY, 2003). 